\title{
AVALIAÇÃO DA ATIVIDADE PROLIFERATIVA DA MUCOSA ORAL DE USUÁRIOS DO CRACK
}

Joslei Carlos BOHN, Cassiano Lima CHAIBEN, Maria Ângela Naval MACHADO, Maria Helena Martins TOMMASI, Antonio Adilson Soares de LIMA

O crack é a forma fumável da cocaína e o seu uso como droga ilícita tem sido apontado como um problema de saúde pública. Os riscos desta droga à saúde da mucosa oral não foram bem descritos. O objetivo deste estudo foi analisar a atividade proliferativa das células epiteliais bucais de usuários de crack usando a coloração das regiões organizadoras nucleolares pela prata (AgNOR). Esfregaços bucais foram realizados na mucosa jugal clinicamente normal por meio da citologia esfoliativa em meio líquido de 60 indivíduos (30 usuários de crack e 30 indivíduos saudáveis não usuários de crack pareados por idade e sexo). As lâminas foram processadas e coradas pela técnica do AgNOR. Em média, os usuários de crack consumiam cerca de 13,3 pedras de crack/dia e a 5,2 anos. Os valores médios da contagem de AgNOR para grupos caso e controle foram, respectivamente, $5,18 \pm 1,83$ e $3,38 \pm 1,02(p<0,05)$. A área de $A g N O R$ e o percentual da área das AgNORs ocupadas no núcleo estavam aumentadas em comparação com o controle $(p<0,05)$. Não houve diferença significativa para os valores médios da área nuclear entre os grupos $(p>0,05)$. Este estudo revelou que o crack induz um aumento da atividade proliferativa das células da mucosa bucal.

Palavras chave: Mucosa bucal; Cocaína Crack; Proliferação Celular; Citologia. 